\title{
Optimization of Process on Extracting Flavonoids from Dry Onion Skins by Alkaline Method
}

\author{
Shi Guoqing ${ }^{1,2,3}$, Xiang Qisen ${ }^{1,3}$, Fan Yichao $^{1}$, Zhao Wenen ${ }^{2}$ and Liu Yanqi ${ }^{*}{ }^{, 1,3}$ \\ ${ }^{I}$ School of Food and Bioengineering, Zhengzhou University of Light Industry, Zhengzhou, Henan, 450002, PR. China \\ ${ }^{2}$ School of Chemical Engineering and Energy, Zhengzhou University, Zhengzhou, Henan, 450001, P.R. China \\ ${ }^{3}$ Henan Collaborative Innovation Center for Food Production and Safety, Zhengzhou, Henan, 450002, PR. China
}

\begin{abstract}
The flavonoids in dry onion skins were extracted by alkaline solution method. On the basis of single factor combined with ternary quadratic regression general rotary unitized design, the effects of several extraction parameters on the extraction efficiency of total flavonoids were investigated, including extraction times, $\mathrm{pH}$ of the extraction solution, material / extraction solution ratio, extraction time, and temperature. $\mathrm{NaNO}_{2}-\mathrm{Al}\left(\mathrm{NO}_{3}\right)_{3}-\mathrm{NaOH}$ method was used for the determination of total flavonoids. The optimal extraction conditions were as follows: two times of extraction; $\mathrm{pH}, 11$; material / extraction solution ratio, $30: 1$; extraction temperature, $83.0 \sim 84.0{ }^{\circ} \mathrm{C}$; extraction duration, $1.9 \sim 2.0 \mathrm{~h}$. Under the above optimal conditions, the flavonoids extracted from dry onion skins yielded $2.82 \%$.
\end{abstract}

Keywords: Flavonoids, extraction, onion skins.

\section{INTRODUCTION}

A growing body of evidence indicates that adequate fruit and vegetable consumption has a role in maintaining health and preventing disease [1-3]. Some of these protective effects may be attributed to flavonoids. It is now increasingly recognised that flavonoids may exert the health-promoting effects, including well-known antioxidant activity and anticancer properties [4-6]. Onions (Allium cepa), one of the most produced vegetable crop, are rich in flavonoids, mainly flavonols [7]. A large number of the outer dry layers of onion bulbs which are not edible and removed before consumption are usually discarded as solid by-product wastes [8]. They may have possible impact on the environment. It is reported that dry onion skins contain high levels of flavonoids, a major class of non-nutrient antioxidants [8-11]. Therefore, it is with economic value and practical significance to recover flavonoids from such onion solid wastes.

Flavonoids are weak acid and can dissolve in alkaline solution. Few authors have focused their attention on the extraction of total flavonoids from dry onion skins using the alkaline aqueous solution. In this study, the alkaline extraction of total flavonoids from dry onion skins was investigated to optimize various extraction conditions using a single factor combined with ternary quadratic regression general rotary unitized design and the mathematical model is set up.

*Address correspondence to this author at the School of Food and Bioengineering, Zhengzhou University of Light Industry, Henan, 450000, P.R. China; Tel: 13938228293; E-mail: liuyanqi@ zzuli.edu.cn

\section{EXPERIMENTAL}

\subsection{Materials and Instruments}

Dry skin waste of red onion was collected from Zhengzhou North Central Vegetable Wholesale Market. Onion skin powder was obtained through being cleaned, dried and ground. Quercetin $(\geq 98 \%)$, from National Institute for Food and Drug Control, China, was used as reference substance. The other reagents are of analytical grade.

SP752 UV-Vis spectrophotometer, Shanghai Spectrum Instruments Co., Ltd; SHZ-2000 multi-function vacuum pump of dual-supporting recycled water, Gongyi Yingyu Instrument Co.; RE-52A rotary evaporator, Shanghai Yarong Biochemical Instrument Co.; HH-2 digital-display thermostat water bath, Jintan Huafeng Instrument Co., Ltd..

\subsection{Extraction of Flavonoids (EOF)}

Several $500 \mathrm{~mL}$ round bottom flasks were added by 5.00 $\mathrm{g}$ onion skin powder, respectively, then added by a certain volume of $\mathrm{NaOH}$ solution with different $\mathrm{pH}$ values. The flasks were bathed under different temperatures for the different time according to experimental design. After that, the extraction liquid was filtered through paper filter. This procedure was repeated twice or more times. The filtrates were then combined in a $500 \mathrm{~mL}$ flask and the same $\mathrm{NaOH}$ solution was added to a final vlolume of $500 \mathrm{~mL}$.

\subsection{Preparation of Standard Solution (POS)}

A standard solution $(0.0101 \mathrm{mg} / \mathrm{mL})$ of quercetin was prepared as follows: quercetin $(20.2 \mathrm{mg})$ was accurately weighed and dissolved in ethanol-water $(60: 40, \mathrm{~V} / \mathrm{V})$ solution, and then the solution was diluted to $100 \mathrm{~mL}$ in a 
volumetric flask $(100 \mathrm{~mL})$ with ethanol-water $(60: 40, \mathrm{~V} / \mathrm{V})$ solvent. $5 \mathrm{~mL}$ of this solution was transferred to a volumetric flask $(100 \mathrm{~mL})$ and diluted to $100 \mathrm{~mL}$ with ethanol-water (60: 40, V/V) solution.

\subsection{Determination of the Wavelength of Flavonoid Colorimetric Analysis}

Firstly, $0.1 \mathrm{~mL}$ of the EOF or $5.0 \mathrm{~mL}$ of the POS was accurately transferred to a volumetric flask $(10 \mathrm{~mL})$, diluted to $5 \mathrm{~mL}$ with ethanol-water (60: 40, V/V) solution, and was added by $0.3 \mathrm{~mL}$ of NaNO2 (5\%) solution, shaken up and then standed for $5 \mathrm{~min}$. Secondly, $0.3 \mathrm{~mL}$ of the $\mathrm{Al}\left(\mathrm{NO}_{3}\right)_{3}$ $(10 \%)$ solution was added to the volumetric flask, shaken, and was left to stand for 6 min. Finally, $4.0 \mathrm{~mL}$ of the $\mathrm{NaOH}$ $(4.0 \%)$ solution was added to the volumetric flask, followed by addition of ethanol-water (60: $40, \mathrm{~V} / \mathrm{V})$ solution to the scale, shaken, and left to stand for $15 \mathrm{~min}$ before determination. Wavelength scanning was performed in a range of $200 \sim 600 \mathrm{~nm}$ using the solution without EOF or POS as reference solution.

The dilute solution of EOF and the quercetin were determinate simultaneously using ethanol-water (60: 40, V / V) solution as reference solution to identify the wavelength of colorimetric analysis.

\subsection{Determination of Total Flavonoids}

The chromogenic methods were often used to determine the content of total flavonoids in foods and herbs by ultraviolet-visible detector [12]. The principle is that most flavonoid molecules contain 3-hydroxyl/4-carbonyl, 5hydroxy/4-carbonyl or ortho-substituting hydroxyl. Aluminum and other metal salts can be complexed by them to form colored complexs. $\mathrm{NaNO}_{2}-\mathrm{Al}\left(\mathrm{NO}_{3}\right)_{3}-\mathrm{NaOH}$ colorimetric method was most commonly used among these chromogenic methods [13]. It is well known that the main components of the onion skin flavonoids are quercetin and its derivatives. Thus, quercetin was selected as standard in the present experiment. Wavelength scanning for the flavonoid extracts and quercetin before and after chromogenic reaction was performed in a range of $200 \sim 600$ nm, as shown in Fig. (1).

It can be seen that in the range of 400 to $600 \mathrm{~nm}$ absorption of quercetin and flavonoid crude extracts was weak and there was not obvious absorption peak. But a very well defined peak at $318 \mathrm{~nm}$ was indicated in the range of 280 to $400 \mathrm{~nm}$. Under less than 280nm, absorption peak was very messy. Therefore, the standard curve for quercetin was drawn at $318 \mathrm{~nm}$.

\subsection{Standard Curve}

Six portions of the POS $(0,1.0,2.0,3.0,4.0$, and $5.0 \mathrm{~mL})$ were accurately removed, respectively, in six volumetric flasks $(10 \mathrm{~mL})$, then chromogenic reaction was carried out as described in determination of the wavelength of flavonoid colorimetric analysis. Using the concentration of quercetin solution as abscissa and the absorbance as y-coordinate, the linear chart was constructed. The standard curve for quercetin is shown in Fig. (2).

Based on the data, linear regression was fitted using the least squares method. The regression equation of quercetin concentration (C) and absorbance (A) was as follows.

$$
A=114.23 C+0.0016
$$
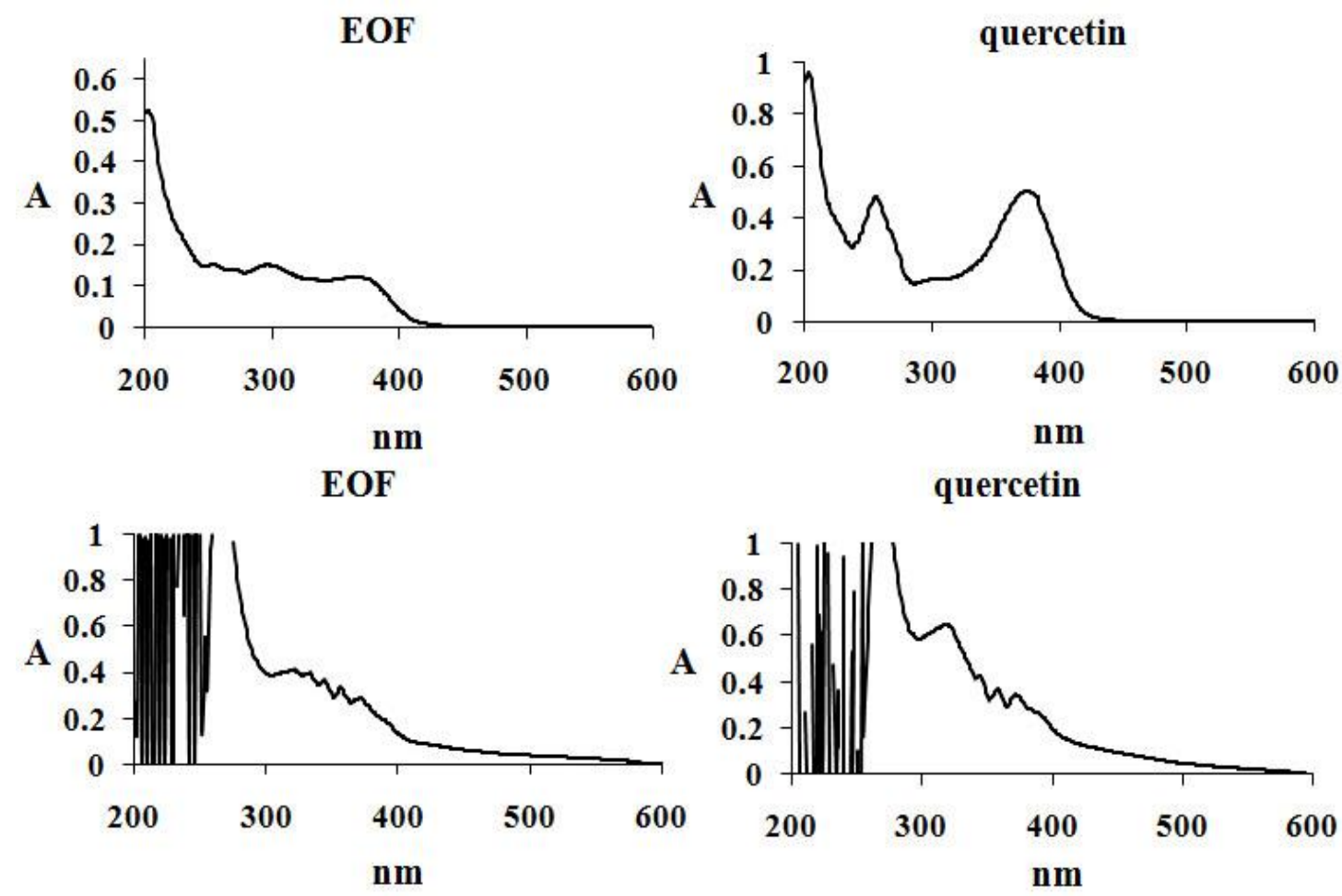

Fig. (1). The wavelength scan on the materials before (upper) and after colorimetric reaction (down). 


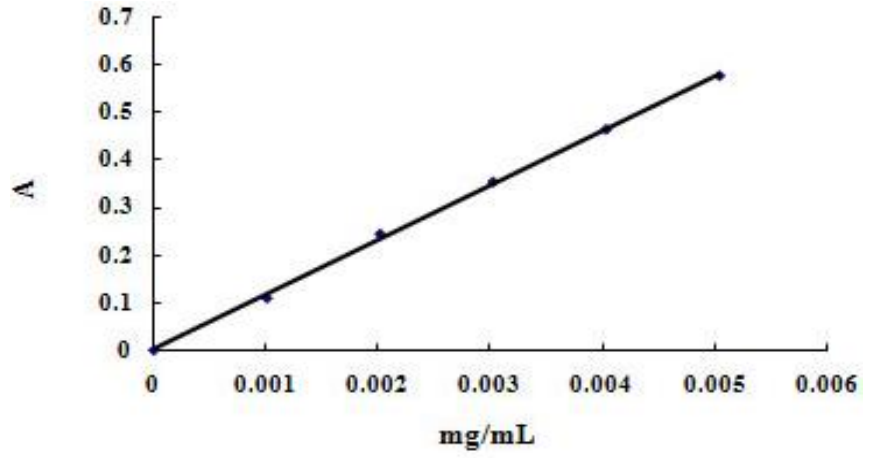

Fig. (2). The standard working curve of quercetin.

\section{RESULTS AND DISCUSSION}

\subsection{Single Factor Test for Flavonoid Extraction from Onion Skins}

\subsubsection{Effect of Different Extraction Times on the Flavonoid Yield}

Extracting flavonoids from dry onion skins was carried out under such conditions as temperature $85^{\circ} \mathrm{C}, \mathrm{NaOH}$ extraction solution/material 30: 1, and $\mathrm{NaOH}$ solution $\mathrm{pH} 11$. Flavonoids were extracted, respectively, through one time, twice, three times, and four times, and extractions were conducted for $2 \mathrm{~h}$ per time. The results are shown in Fig. (3).

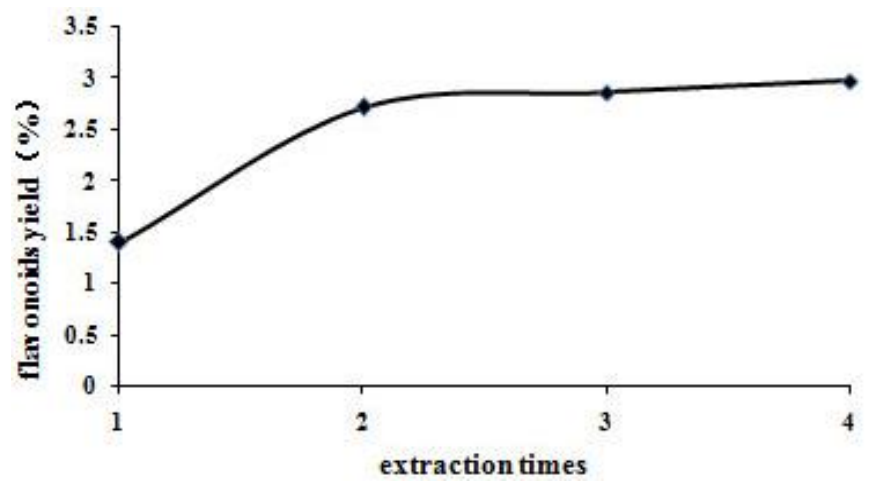

Fig. (3). Effect of extraction times on the flavonoid yield.

The flavonoid yields were $47.4 \%, 43.8 \%, 5.0 \%$, respectively, when extractions were conducted one time, twice, and three times. The most of flavonoids were extracted from the materials after twice extractions. Flavonoid yields hardly increased with increasing extraction times to three times and more times. Moreover, increasing extraction times will increase the use of alkaline solution, which not only pollutes the environment but also increases difficulty in dealing with solvent and obtaining flavonoids. Taking into account cost, extraction times were optimized as twice.

\subsubsection{Effect of Extraction Solution pH on the Flavonoid Yield}

Flavonoid extraction conditions was temperature $85^{\circ} \mathrm{C}$ and $\mathrm{NaOH}$ extraction solution/material 30:1. Extractions were conducted twice for $2 \mathrm{~h}$ per time. The $\mathrm{pH}$ of the extraction solution was adjusted, respectively, to 1, 3, 5, 7, 8,
9, 10, 11, 12, 13. Flavonoid yield obtained is shown in Fig. (4).

From Fig. (4), when $\mathrm{pH}<7$, the flavonoid yield was low and increased slowly with the increase of extraction solution $\mathrm{pH}$ value. When $\mathrm{pH}$ was 7 to 13 , the flavonoid yield first increased and then decreased. The flavonoid yield was the biggest at $\mathrm{pH} 11$. This is because the flavonoids show a weak acid, alkaline environment favors flavonoid extraction, but when alkali is too strong, flavonoids are oxidized easily.

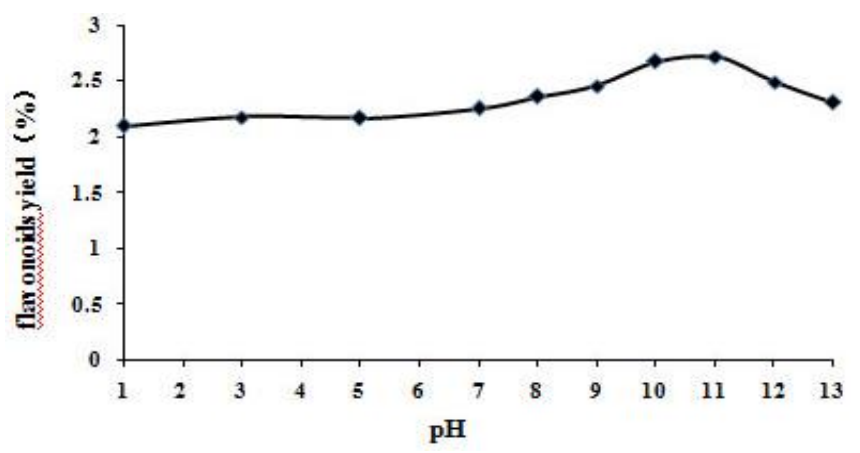

Fig. (4). Effect of extraction solution $\mathrm{pH}$ on flavonoid yield.

\subsubsection{Effect of Ratio of NaOH Extraction Solution and Material on the Flavonoid Yield}

Extracting flavonoids from dry onion skins was carried out under such conditions as temperature is $85^{\circ} \mathrm{C}$ and $\mathrm{NaOH}$ solution $\mathrm{pH}$ 11. Ratios between $\mathrm{NaOH}$ extraction solution and the materials were $10: 1,20: 1,30: 1,40: 1,50: 1$, respectively, and extractions were conducted twice for $2 \mathrm{~h}$ per time.

As shown in Fig. (5), the yield of flavonoids gradually increased with the increasing of ratio of $\mathrm{NaOH}$ solution / material. When the ratio between $\mathrm{NaOH}$ solution and the materials increased to $30: 1$ and more, there was a little change in the flavonoids yield. Considering solvent usage, energy consumption and other factors, the ratio of $30: 1$ was optimum for the high yield of flavonoids.

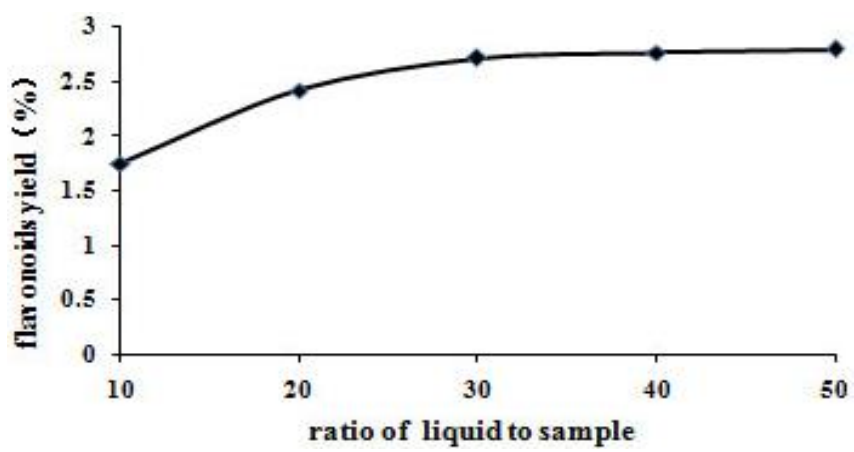

Fig. (5). Effect of material-extraction solution ratio on the flavonoid yield.

\subsubsection{Effect of Extraction Duration on the Flavonoid Yield}

Extracting flavonoids from dry onion skins was carried out under $85^{\circ} \mathrm{C}, \mathrm{NaOH}$ extraction solution/material 30: 1, and $\mathrm{NaOH}$ solution $\mathrm{pH}$ 11. Extractions were conducted twice for $0.5 \mathrm{~h}, 1 \mathrm{~h}, 1.5 \mathrm{~h}, 2.0 \mathrm{~h}, 2.5 \mathrm{~h}$, and $3 \mathrm{~h}$ per time, respectively. Flavonoid yield obtained is shown in Fig. (6). 
It an be seen that flavonoid yield first increased with the increase of extraction time and then decreased over $2 \mathrm{~h}$. This showed that flavonoids in onion skins can be fully dissolved and reach the dissolution equilibrium within two hours. The yield decrease after two hour is because flavonoids were damaged in alkaline and heating environment for a long time.

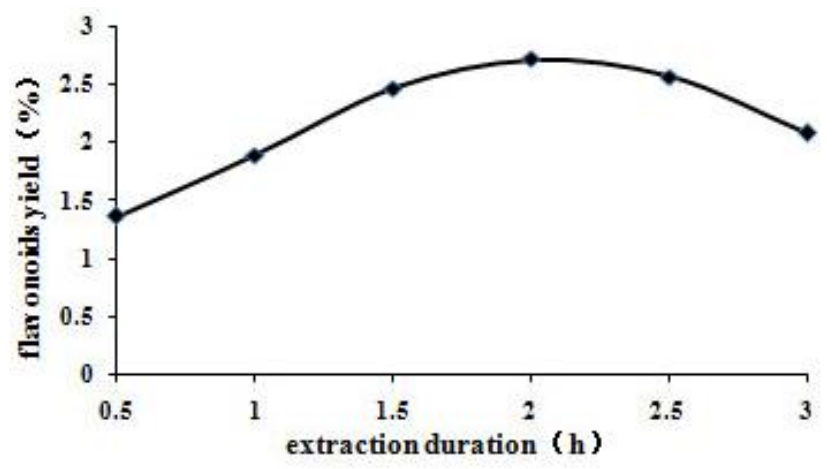

Fig. (6). Effect of extraction duration on the flavonoid obtained.

\subsubsection{Effect of Extraction Temperature on the Flavonoid Yield}

Extracting flavonoids from dry onion skins was carried out under $\mathrm{NaOH}$ extraction solution/material $30: 1$ and $\mathrm{NaOH}$ solution $\mathrm{pH}$ 11. Under the above conditions, extraction temperatures were $30^{\circ} \mathrm{C}, 40^{\circ} \mathrm{C}, 55^{\circ} \mathrm{C}, 70^{\circ} \mathrm{C}, 85^{\circ} \mathrm{C}$, $100^{\circ} \mathrm{C}$, respectively, and extractions were conducted twice for $2 \mathrm{~h}$ per time. It can be seen from Fig. (7) that the flavonoid yield increased at first and then decreased with extraction temperature increasing. The increasing rate of the flavonoid yield between $30^{\circ} \mathrm{C} \sim 70^{\circ} \mathrm{C}$ was low and the rate became very high between $70^{\circ} \mathrm{C} \sim 85^{\circ} \mathrm{C}$, the flavonoid yield was the highest at $85^{\circ} \mathrm{C}$, and over $85^{\circ} \mathrm{C}$, the flavonoid yield decreased rapidly. This may be due to the effect of temperature on the solubility of flavonoids, but too high temperature not only increased the solubility of impurities also led to the oxidation of flavonoids.

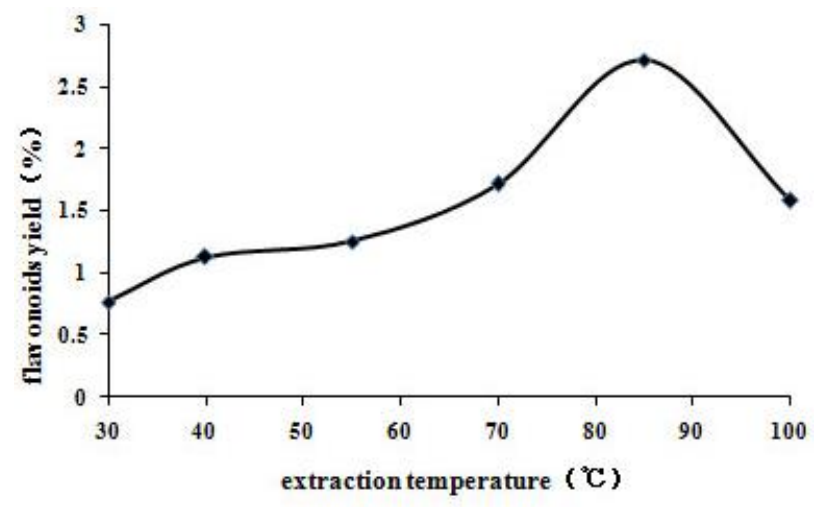

Fig. (7). Effect of extraction temperature on the flavonoid yield.

\subsection{Ternary Quadratic Regression General Rotational Combinational Design}

\subsubsection{Experimental Design}

The flavonoid yield extracted from dry onion skins was affected by extraction temperature, time, liquid/material ratio and other factors, furthermore, these factors were affected by each other. In order to find the optimal extraction conditions, the effects of these factors on the extraction rate were investigated comprehensively.

Orthogonal test is a very useful experimental design which helps obtain good results through less experimental number. However, the optimal conditions obtained by this design can only be limited to a given level of factors rather than all the levels of factors. Regression design is an effective data processing method. The experimental results may be predicted through determining the regression equation. But it can only passively analyze and process experimental data. Regression orthogonal design combines the advantages of these designs. It not only is reasonable and needs less experiment number, but also may make a mathematical model. The quadratic general rotary unitized design may partly eliminate the correlation between regression coefficients by sacrificing the orthogonal part, thus, the predicted variance is equal from the regression equation of various points on the spherical surface which has equal distance from the test central point. On the one hand, this design retains such advantages as less experimental number and easy calculation in orthogonal design, on the other hand, it helps overcome the shortcoming that the variance of the predictive values from quadratic regression in orthogonal design depends on the position of the test points in the factor space, and directly find the optimal region according to predictive values.

In the present experiment, the extraction process is optimized using ternary quadratic general rotary unitized design referring to the data of the single factor test in which the absorbance corresponding to the amount of total flavonoids in $5 \mathrm{~g}$ onion skin extract sets as the objective function, extraction temperature $\left({ }^{\circ} \mathrm{C}\right)$, extraction time $(\mathrm{h})$, and ratio of extraction solution and material (V/W) set as regulatory factors. Coded values of the treatment variables are shown in Table $\mathbf{1}$

Experiment design and the resultsobtained are shown Table 2.

Regression analysis was conducted based on the absorbance using the response surface regression (SAS RSREG) procedure of statistical software SAS (9.1 SAS Institute Inc., Cary, NC, USA) [14]. The test results are shown in Table 3.

The data in Table $\mathbf{3}$ were analysed in accordance with the standard quadratic polynomial regression. The regression equation of absorbance corresponding to the flavonoid extracts was obtained.

$$
\begin{aligned}
& Y=0.315000-0.009688 X_{1}+0.0000635 X_{2}+0.008687 X_{3}- \\
& 0.025750 X_{1}^{2}+0.003625 X_{1} X_{2}-0.005375 X_{2}^{2}-0.001875 X_{1} X_{3}- \\
& 0.001625 X_{2} X_{3}-0.003000 X_{3}^{2}
\end{aligned}
$$

It can be seen from the analysis of variance in quadratic regression model that $\mathrm{P}<0.0001$, the regression model is of significant level, and the correlation coefficient (R2) is 0.9536 , indicating that $95.36 \%$ of the experimental data can be explained using this equation. In this model, the correlation coefficients of the liner term, of the quadratic term, and of the interaction terms are $0.1193,0.8274,0.0068$, 
Table 1.' Coded values of the treatment variables.

\begin{tabular}{|c|c|c|c|}
\hline \multirow{2}{*}{ Coded values } & \multicolumn{3}{|c|}{ Factors } \\
\cline { 2 - 4 } & Extraction temperature $\mathbf{X}_{\mathbf{1}} /{ }^{\circ} \mathbf{C}$ & Extraction time $\mathbf{X}_{\mathbf{2}} / \mathbf{h}$ & Extraction solution : $\mathbf{m a t e r i a l} \mathbf{X}_{\mathbf{3}} / \mathbf{V} / \mathbf{W}$ \\
\hline \hline-2 & 70 & 1.5 & $20: 1$ \\
\hline-1 & 77.5 & 1.75 & $25: 1$ \\
\hline 0 & 85 & 2 & $30: 1$ \\
\hline 1 & 92.5 & 2.25 & $35: 1$ \\
\hline 2 & 100 & 2.5 & $40: 1$ \\
\hline Changes in value $(\Delta)$ & 7.5 & 0.25 & $5: 1$ \\
\hline
\end{tabular}

Table 2. Experiment design and the results.

\begin{tabular}{|c|c|c|c|c|}
\hline The number of Experiment & $\mathbf{X}_{1}$ & $\mathbf{X}_{2}$ & $\mathbf{X}_{3}$ & $\mathbf{Y}(\mathbf{A})$ \\
\hline 3 & 1 & -1 & 1 & 0.317 \\
\hline 4 & 1 & -1 & -1 & 0.279 \\
\hline 6 & -1 & 1 & -1 & 0.217 \\
\hline 7 & -1 & -1 & 1 & 0.361 \\
\hline 8 & -1 & -1 & -1 & 0.341 \\
\hline 9 & 2 & 0 & 0 & 0.193 \\
\hline 12 & 0 & -2 & 0 & 0.294 \\
\hline 13 & 0 & 0 & 2 & 0.327 \\
\hline 14 & 0 & 0 & -2 & 0.289 \\
\hline 15 & 0 & 0 & 0 & 0.317 \\
\hline 16 & 0 & 0 & 0 & 0.309 \\
\hline 17 & 0 & 0 & 0 & 0.311 \\
\hline 18 & 0 & 0 & 0 & 0.324 \\
\hline
\end{tabular}

respectively. Significance test of the regression equation coefficients showed that the effects of the liner term and the quadratic term on the experimental results was of significant level, and the interaction of various factors was not significant. Rms (Root MSE) is 0.009003. The analysis of the residual showed that the lack of fit of regression model is not significant, indicating that the quadratic equation can better fit the actual extraction experiments.

\subsection{2. $t$-Test of the Regression Model}

t-Test showed that $\mathrm{P}<0.01$ in $\mathrm{X}_{1}, \mathrm{X}_{3}, \mathrm{X}_{1} \mathrm{X}_{1}$ and $\mathrm{X}_{2} \mathrm{X}_{2}$ of the equation (2), the interaction of various factors was not 
Table 3. Regression analysis.

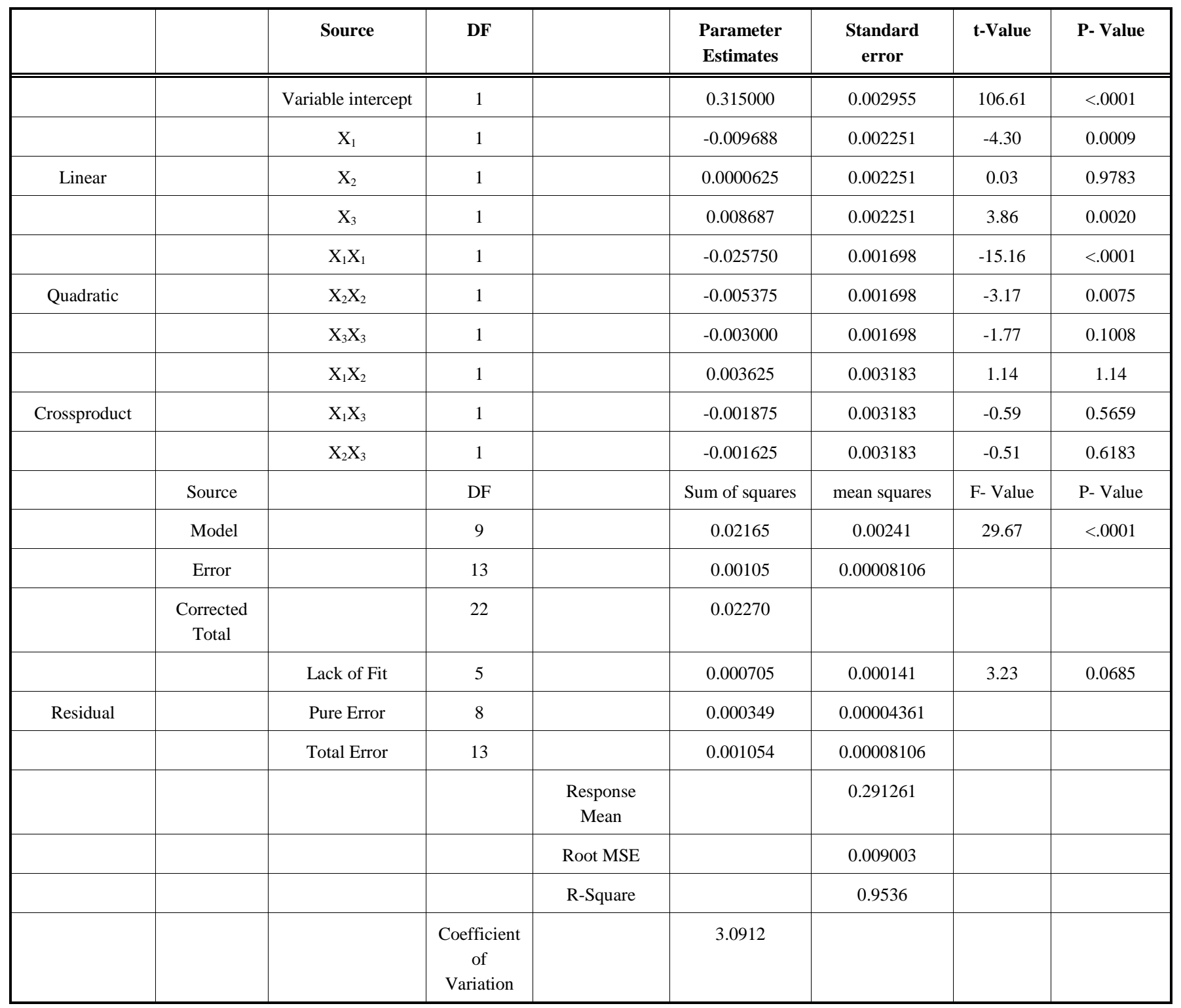

significant. The term in $\mathrm{P}>0.25$ had little effect on the absorbance and can be negligible. Therefore, the regression equation can be abbreviated as follows:

$$
\begin{aligned}
& Y=0.315000-0.009688 X_{1}+0.008687 X_{3}- \\
& 0.025750 X_{1}^{2}-0.005375 X_{2}^{2}
\end{aligned}
$$

\subsubsection{Analysis of key factors}

In order to analyze the separate impact of each single factor on the extraction rate of total flavonoids from onion skin, two other factors in the regression equation (3) fixed at zero level and the partial sub-regression equation of the third factor was obtained through the dimensionality reduction:

$$
\begin{aligned}
& y_{1}=0.315000-0.009688 X_{1}-0.025750 X_{1}^{2} \\
& y_{2}=0.315000-0.005375 X_{2}{ }^{2}
\end{aligned}
$$

$\mathrm{y}_{3}=0.315000+0.008687 X_{3}$

The derivative can be respectively obtained.

$\mathrm{d} y_{1} / d x_{1}=-0.009688-0.0515 X_{1}$

$\mathrm{d} y_{2} / d x_{2}=-0.01075 X_{2}$

$\mathrm{d} y_{3} / d x_{3}=0.008687$

If $\mathrm{dyi} / \mathrm{dxi}=0(\mathrm{i}=1,2)$, most appropriate amount of the main factors alone can be derived when the $\mathrm{y}_{\mathrm{i}}$ is of great value: $\mathrm{X}_{1}=-0.188, \mathrm{X}_{2}=0$. Equation (4') - (6') show that the effect orders of the main factors on the extraction rate are temperature $\left(\mathrm{X}_{1}\right)>$ liquid ratio $\left(\mathrm{X}_{3}\right)>$ extraction time $\left(\mathrm{X}_{2}\right)$.

According to these equations, the curve of the absorbance to the three factors is obtained and shown in Fig. (8).

Fig. (8) shows that the temperature is the most significant influencing factor. As the temperature changes, the parabola 


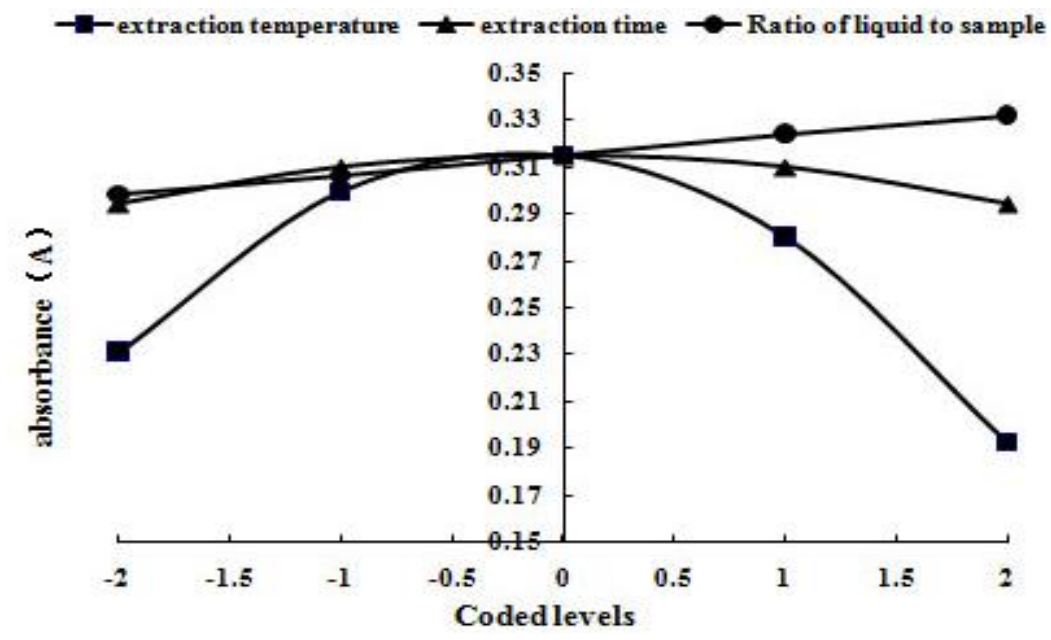

Fig. (8). Effect of single factors on absorbance.

Table 4. The canonical parse of response surface based on coding (stable point).

\begin{tabular}{|c|c|c|c|c|c|c|c|}
\hline \multirow[t]{2}{*}{ Factor } & \multirow[t]{2}{*}{ Coded } & \multirow[t]{2}{*}{ Uncoded } & \multirow{2}{*}{$\begin{array}{c}\text { Predicted } \\
\text { value Y (A) }\end{array}$} & & $\begin{array}{c}\text { Eigen } \\
\text { vectors }\end{array}$ & & \multirow[t]{2}{*}{ Eigen values } \\
\hline & & & & $\mathbf{X}_{1}$ & $\mathbf{X}_{2}$ & $\mathbf{X}_{3}$ & \\
\hline $\mathrm{X}_{1}$ & -0.135213 & -0.270426 & & -0.063791 & -0.324649 & 0.943681 & -0.010628 \\
\hline $\mathrm{X}_{2}$ & -0.165277 & -0.330555 & 0.323345 & 0.069174 & 0.941894 & 0.328711 & -0.022102 \\
\hline
\end{tabular}

changes of the absorbance are significant. At about -2 to -1 , the absorbance increases rapidly, at $-1 \sim 0$, the absorbance increases slowly, the absorbance is maximum around 0 , then decreases rapidly. The graphics of the extraction time effect on the absorbance is a gently downward and symmetrical parabola. The extraction rate did not rise but fell with time increase. It may be attributed to the idea that flavonoids degradated partly under relatively high temperature for a long time. The absorbance increased linearly with increaseing in the ratio of extraction solution to material, but the range of increase was small.

\subsection{Optimization of Extraction Process}

Principal component analysis was conducted to the equation (3') using the SAS RSREG procedure. A stable point was obtained, shown in Table 4.

Its characteristic values are (-0.010628, -0.022102, 0.103770 ) and all negative. According to the design principle, $\mathrm{Y}$ should have a maximum value. The data was processed and optimized. The coded combination with maximum $Y$ was obtained as: $\mathrm{X}_{1}=-0.270426 \sim-0.135213, \mathrm{X}_{2}$ $=-0.330555 \sim-0.165277, \quad X_{3}=0.810975 \sim 1.621950$, and namely, extraction temperature: $83.0 \sim 84.0^{\circ} \mathrm{C}$, extraction time: $1.9 \sim 2.0 \mathrm{~h}$, the ratio of extraction solution and material: $34.1 \sim 38.1$ : 1 , and the maximum absorbance is 0.323345 . Based on the regression equation $A=114.23 C+0.0016$, extraction concentration $\mathrm{C}$ is calculated, and the maximum flavonoid yield is $2.82 \%$ when $\mathrm{C}$ calculated is placed in the equation (1).
The average values of the extraction conditions are: temperature $83.5^{\circ} \mathrm{C}$, time $1.9 \mathrm{~h}$, the ratio of extraction solution and material $36: 1$. Under such experimental conditions, the flavonoid yield from dry onion skins reached $2.82 \%$, and was consistent with the result by theoretical calculation.

\section{CONCLUSION}

Using quadratic regression rotary orthogonal unitized design, mathematical model was established as:

$$
\begin{aligned}
& Y=0.315000-0.009688 X_{1}+0.008687 X_{3}-0.025750 X_{1}{ }^{2}- \\
& 0.005375 X_{2}{ }^{2}
\end{aligned}
$$

the extraction rate $(Y)$, temperature $\left(\mathrm{X}_{1}\right)$, time $\left(\mathrm{X}_{2}\right)$, the ratio of extraction solution and material $\left(\mathrm{X}_{3}\right)$.

The optimum conditions of flavonoids extracted from onion skins by the alkaline method are: temperature $83.0 \sim 84.0^{\circ} \mathrm{C}$, duration $1.9 \sim 2.0 \mathrm{~h}$, the ratio of extraction solution and material 34 38:1, and extraction is conducted twice under such conditions. The total onion flavonoid yield may be up to $2.82 \%$. The relative size of the factors involved in rotary orthogonal experiments is extraction temperature $\left(\mathrm{X}_{1}\right)>$ the ratio of extraction solution and material $\left(\mathrm{X}_{3}\right)>$ extraction time $\left(\mathrm{X}_{2}\right)$.

\section{CONFLICT OF INTEREST}

The authors confirm that this article content has no conflict of interest. 


\section{ACKNOWLEDGEMENTS}

Declared none.

\section{REFERENCES}

H.C. Hung, K.J Joshipura, R. Jiang, F.B. Hu, D. Hunter, S.A. Smith-Warner, G.A. Colditz, B. Rosner, D. Spiegelman, and W.C. Willett, "Fruit and vegetable intake and risk of major chronic disease", J. Natl. Cancer Inst., vol. 96, pp. 1577-1584, 2004.

[2] M.A. Van Duyn, and E. Pivonka, "Overview of the health benefits of fruit and vegetable consumption for the dietetics professional: selected literature", J. Am. Diet. Assoc., vol. 100, pp. 1511-152, 2000.

[3] C. La Vecchia, and A. Tavani, "Vegetables, fruit, antioxidants and cancers; a review of italian studies", Eur. J. Nutr., vol. 40, pp. 261267, 2001.

[4] Z. Huang, B. Wang, D.H. Eaves, J.M. Shikany, and R.D. Pace, "Phenolic compound profile of selected vegetables frequently consumed by African Americans in the southeast United States", Food Chem., vol. 103, pp. 1395-1402, 2007.

[5] L.H. Yao, Y.M. Jiang, J. Shi, F.A. Tomas-Barberan, N. Datta, R. Singanusong, and S.S. Chen, "Flavonoids in food and their health benefits", Plant Foods Human Nutr., vol. 59, pp. 113-122, 2004

[6] B.H. Havsteen, "The biochemistry and medical significance of the flavonoids", Pharmacol. Ther., vol. 96, pp. 67-202, 2002.
P.C.H. Hollman, and I.C.W. Arts, "Flavonols, flavones and flavanols - nature, occurrence and dietary burden", J. Sci. Food Agric., vol. 80, pp. 1081-1093, 2000.

[8] Z. Khiari, D.P. Makris, and P. Kefalas, "An investigation on the recovery of antioxidant phenolics from onion solid wastes employing water/ethanol-based solvent systems", Food Bioprocess Technol., vol. 2, pp. 337-343, 2009.

[9] T.N. Ly, C. Hazama, M. Shimoyamada, H. Ando, K. Kato, and R. Yamauchi, "Antioxidative compounds from the outer scales of onion", J. Agric. Food Chem., vol. 53, pp. 8183-8189, 2005.

[10] E. Kiassos, S. Mylonaki, D.P. Makris, and P. Kefalas, "Implementation of response surface methodology to optimise extraction of onion (Allium cepa) solid waste phenolics", Food Sci. Emerg. Technol., vol. 10, pp. 2 46-252, 2009.

[11] E.Y. Jin, S. Lim, S.O. Kim, Y.S. Park, J.K. Jang, M.S. Chung, H. Park, K.S. Shim, and Y.J. Choi, "Optimization of various extraction methods for quercetin from onion skin using response surface methodology", Food Sci. Biotechnol., vol. 20, pp. 1727 1733, 2011.

[12] X. Yao, Natural pharmaceutical chemistry: $2^{\text {nd }}$ ed. People's Medical Publishing House, Beijing, China, 1994, pp. 199.

[13] China Pharmacopoeia Committee, Chinese Pharmacopoeia part I. Beijing, China. 2005, pp. 256.

[14] R.H. Myers, and D.C. Montgomery, Response surface methodology: process and product optimization using designed experiment, New York, N Y, USA, 2002.

(C) Guoqing et al.; Licensee Bentham Open.

This is an open access article licensed under the terms of the Creative Commons Attribution Non-Commercial License (http://creativecommons.org/licenses/ by-nc/3.0/) which permits unrestricted, non-commercial use, distribution and reproduction in any medium, provided the work is properly cited. 